\title{
Selective Separation and Analysis of Pb(II) Using a New Surface Imprinted Multi-Walled Carbon Nanotubes Combined with AAS
}

\author{
Haisheng Zhang ${ }^{1}$, Weiping Zhou ${ }^{2}$, Hongqing Wang ${ }^{1}$, Yuyuan Wang ${ }^{1}$, Fangfang $\mathrm{He}^{1}$, Zhiqiang Cheng ${ }^{1}$, \\ Honglin Li ${ }^{1}$, Jinhui Tang ${ }^{1}$ \\ ${ }^{1}$ School of Chemistry and Chemical Engineering, University of South China, Hengyang, China; ${ }^{2}$ College of Mathematics and Physi- \\ cal, University of South China, Hengyang, China. \\ Email: *hqwang2009cn@yahoo.com.cn
}

Received March $2^{\text {nd }}, 2012$; revised March 20 $0^{\text {th }}, 2012$; accepted April 10 $0^{\text {th }}, 2012$

\begin{abstract}
A new surface ion-imprinted Multi-walled carbon nanotubes (MCNTs), which was 6,6'-((1E,1'E)-(pyridine-2,6-diylbis(azanylyl))bis(methanylylidene))bis(2-allyl-phenol) and $\mathrm{Pb}$ (II) complex as functional monomer and template ion was presented for extracting and enrichment traces of $\mathrm{Pb}(\mathrm{II})$ ion. Parameters affecting the recovery of $\mathrm{Pb}$ (II) have been investigated in detail. The novel IMCNTs display high affinity, specificity, and selectivity for $\mathrm{Pb}$ (II) with a maximum uptake capacity of $115.5 \mathrm{mg} \cdot \mathrm{g}^{-1}$ at $\mathrm{pH}$ 4.0. Meanwhile, only 11 mins was enough for extracting $98.5 \% \mathrm{~Pb}$ (II) for the IMCNTs. No significant loss in adsorption capacity is observed when the IMCNTs are reused for eleven times. Separation and preconcentration with IMCNTs particles results in a limit of detection of $0.47 \mu \mathrm{g} \cdot \mathrm{L}^{-1}(3 \sigma)$ and RSD $(\mathrm{n}=8)$ of $1.16 \%$ by using atomic absorption spectrophotometer (AAS).
\end{abstract}

Keywords: Lead Determination; Ion Imprinted Particles; Carbon Nanotube; Selective Recognition

\section{Introduction}

Soil and water pollution, caused by toxic heavy metals, is a major environmental concern [1]. Among toxic heavy elements, lead is one of the commonest for animals and humans, even at lower concentrations [2,3]. Unlike organic compounds, lead is non-biodegradable and accumulative through its interaction with inorganic and organic materials, including adsorption, formation of complexes and chemical combinations etc. [4]. Consequently, the development of reliable methods for the removal and determination of lead from environment is of particular significance $[5,6]$. However, for conventional techniques, determining lead is very difficult due to its low concentrations in environmental samples and matrix interference. Thus, an effective enrichment and separation process is usually necessary prior to determination.

In recent years, Surface imprinting technique (SIT) has become a powerful method for high selectivity adsorption of target metal ions [7]. It is flexible, economical, environmental-friendly, highly selective, speedy, simple, rich in accessible sites, safe, easily automatic, and quick in mass transfer and binding kinetics [8-10]. The particularly promising applications of SIT are trace enrichment and

"Corresponding author. trace separation [8-12]. SIT is mainly based on the utilization of inorganic and organic solid sorbents which possess a stable and insoluble porous matrix having suitable active groups (typically organic groups) to interact with metal ions. Silica gel $[13,14]$ and MCNTs [15] are ideal supports for organic groups. There are some reports about the enrichment and separation of $\mathrm{Pb}(\mathrm{II})$, using SIT with silica gel as the support $[2,3,6]$. However, there is few report on the synthesis of IMCNTs for Pb(II) extraction.

The classical preparation procedure of ion-imprinted polymer is collecting template molecule, functional monomer and cross-linker together to compounding. But the template molecule with functional monomer often isn't monogamous combination in ion-imprinted polymer. The coordination effect between metal ion and ligand is forceful, combination quickly, steady, convenient [16]. So, the coordination effect between metal ion and ligand is a top choice in SIT progress. The kinds of o-Hydroxyphenol Schiff base chemical compound have very well coordination capability with metal ions $[17,18]$. In order to increase relative selectivity of absorbent for $\mathrm{Pb}(\mathrm{II})$, a novel complex of 6,6'-((1E,1'E)-(pyridine-2,6-diylbis (azanylyl))bis(methanylylidene))bis(2-allylphenol)w(PD 
ABMBAPOL) with $\mathrm{Pb}(\mathrm{II})$ was synthesized as functional monomer and template molecule of ion-imprinted polymer in this study. Meanwhile, a new surface-grafted $\mathrm{Pb}(\mathrm{II})-$ imprinted carbon nanotubes sorbent was presented. Parameters affecting the separation and pre-concentration of $\mathrm{Pb}$ (II) from aqueous solution were also discussed. Finally, a new method for determining traces of $\mathrm{Pb}$ (II) was developed.

\section{Materials and Methods}

\subsection{Reagents and Chemicals}

Analytical and spectral grade chemicals and doubly distilled water (DDW) were used throughout the experiments. $0.1 \mathrm{M} \mathrm{HNO}_{3}$ or $0.1 \mathrm{M} \mathrm{NH}_{3} \cdot \mathrm{H}_{2} \mathrm{O}$ were utilized for adjusting $\mathrm{pH}$ of solutions. Standard solutions (1.0 $\left.\mathrm{mg} \cdot \mathrm{mL}^{-1}\right)$ of $\mathrm{Pb}(\mathrm{II}), \mathrm{Cd}(\mathrm{II}), \mathrm{Cu}(\mathrm{II})$ and $\mathrm{Ni}(\mathrm{II})$, containing $1.0 \% \mathrm{HNO}_{3}$, were prepared by dissolving corresponding amounts of nitrate salts in DDW.

3-Allylsalicylaldehyde, 2,6-Diaminopyridine, Acrolein, and 2,2'-azobisisobutyronitrile (AIBN) (98\%) were offered by Aladdin. 3-Aminopropy ltrimethoxysilane (APS) and ethylene glycol dimethacrylate (EGDMA) were purchased from Golden Dragon Industrial (HK) Co., Ltd. MCNTs was supplied by Shenzhen Nanotech Port Co. Ltd. Lead standard liquid (GBW08619) was supplied by National Institute of Metrology. Other chemicals were purchased from J\&K scientific LTD.

\subsection{Apparatus}

Scanning Electron Microscope (SEM, JEOL JSM 6700 F) was used to study the morphology and shape of the MCNTs. A Perkin-Elmer Lambda 45 AAS spectrometer was used for determining concentrations of metal ions. IR Spectra $\left(4000-400 \mathrm{~cm}^{-1}\right)$ in $\mathrm{KBr}$ pellets were recorded using IR Prestige-21 from Shimadzu. 1H-NMR spectra were taken on a Varian XL-300 Spectrometer with TMS as the internal reference and $\mathrm{CD}_{3} \mathrm{COCD}_{3}$ as the solvents. A pHs-3 C digital $\mathrm{pH}$ meter was used for measuring $\mathrm{pH}$.

\subsection{Preparation of Samples}

Natural water samples were taken locally. River water came from Xiangiiang River, Hengyang, China. The Tap water was collected from our laboratory. The waste water was obtained from lead-zinc mine of Songbai, Hengyang, China. Before filled with the water samples, polyethylene bottles were cleaned with detergent, water, diluted nitric acid and DDW in sequence. All water samples were filtered through a $0.45 \mu \mathrm{m}$ membrane filter and adjusted to $\mathrm{pH} 4$ with the diluted $\mathrm{HNO}_{3}$ and $\mathrm{NH}_{3} \cdot \mathrm{H}_{2} \mathrm{O}$.

\subsection{Preparation of IMCNTs and Non-IMCNTs}

\subsubsection{Synthesis of \\ 6,6'-((1E,1'E)-(pyridine-2,6-diylbis(azanylyl)) \\ bis(methanylylidene))bis-(2-allylphenol)}

The functional monomer was prepared as the literature [19]. Firstly, $100 \mathrm{~mL}$ methanol $(\mathrm{MeOH})$ and 3-Allylsalicylaldehyde $(2.97 \mathrm{~g})$ were added to a three-neck flask one after another. Then, 2,6-Diaminopyridine $(1.00 \mathrm{~g})$ in $60 \mathrm{~mL} \mathrm{MeOH}$ was added dropwise to the above solution under stirring at room temperature. After being continuously stirred for $2 \mathrm{~h}$ at room temperature, many yellow solids were obtained by filter. Recrystallization of the yellow compound with $\mathrm{CH}_{2} \mathrm{Cl}_{2}$ and $n$-hexane (2:1), gave 2.38 g yellow crystals.

Yield: $2.38 \mathrm{~g} \mathrm{(60 \% ),} \mathrm{mp:} 162.1^{\circ} \mathrm{C}-162.8^{\circ} \mathrm{C}, 1 \mathrm{H}-\mathrm{NMR}$ : $\left(\mathrm{CD}_{3} \mathrm{COCD}_{3}, \mathrm{~d}\right.$ ppm) $, \delta: 3.48\left(\mathrm{~d}, 4 \mathrm{H}, \mathrm{CH}_{2}\right), 5.04-5.14$ (m, 4H, $\left.\mathrm{CH}_{2}\right), 6.04-6.09(\mathrm{~m}, 2 \mathrm{H}, \mathrm{CH}), 6.96-8.08(\mathrm{~m}$, 9H, Ar), 9.70 (s, 2H, CH). FT-IR $\left(\mathrm{KBr}, \mathrm{cm}^{-1}\right) \gamma: 3633.89$ (O-H); 3045.60 (C-H of Ar-C-H); 2938.10, 2870.67(C-H); 1683.74 $(\mathrm{C}=\mathrm{N}) ; 1662.32(\mathrm{C}=\mathrm{C}) ; 1608.04(\mathrm{C}=\mathrm{N}$, pyridine); 1487.56, $1450.21(\mathrm{Ar}-\mathrm{C}=\mathrm{C})$.

\subsubsection{Synthesis of MCNTs Functionalized by Amino-Group}

MCNTs were first hydroxylated according to literature [20]. Then, they were functionalized with amino to prepare $\mathrm{MCNTs}-\mathrm{NH}_{2}$ as described in literature [21]. The typical process was as following. Under stirring, $4 \mathrm{ml}$ of 3 -aminopropyltriethoxysilane was added to the mixture of MCNTs-OH $(4.01 \mathrm{~g})$ and dry-toluene $(100 \mathrm{ml})$. After the reactions proceeded for $24 \mathrm{~h}$ at room temperature, the MCNTs- $\mathrm{NH}_{2}$ was obtained by centrifugation, followed by redispersion in methanol and centrifugation for three times.

\subsubsection{Synthesis of Vinyl-Group-Functionalized MCNTs}

Under stirring, $4 \mathrm{~mL}$ acrolein (dissolved in $10 \mathrm{~mL} \mathrm{MeOH}$ ) was added dropwise to a solution of MCNTs- $\mathrm{NH}_{2}(1.90$ g) and $\mathrm{MeOH}(90 \mathrm{~mL})$. After reacting for $3 \mathrm{~h}$ at room temperature, the reaction solution was centrifugated, resulting in the solid nanoparticles Vinyl-Group-Functionalized MCNTs (MCNTs-CH= $\mathrm{CH}_{2}, 1.99 \mathrm{~g}$ ) which was then washed with $\mathrm{MeOH} / \mathrm{DDW} / \mathrm{DMF}$ (1:1:1 in volume).

\subsubsection{Synthesis of IMCNTs and Non-IMCNTs [22]}

The synthesis process of IMCNTs, whose surface was grafted by $\mathrm{Pb}(\mathrm{II})$-imprinted group, is presented as Scheme 1. Firstly, $0.76 \mathrm{~g}\left(\mathrm{CH}_{3} \mathrm{COO}\right)_{2} \mathrm{~Pb} \cdot 3 \mathrm{H}_{2} \mathrm{O}$ was dissolved in $25 \mathrm{~mL} \mathrm{MeOH}$. Then, this solution was slowly added to a glass reactor containing the functional monomer (PDABMBAPOL, $1.59 \mathrm{~g}$ ) in DMF $(25 \mathrm{~mL})$ under 
stirring. After the mixture was stirred for $3 \mathrm{~h}$ at room temperature, MCNTs- $\mathrm{CH}=\mathrm{CH}_{2}(2.01 \mathrm{~g})$, AIBN $(0.10 \mathrm{~g})$ and EGDMA ( $4 \mathrm{~mL})$ were added. Then, nitrogen was bubbled in to drive away oxygen in the reactor for 25 mins. After being kept stirred for $24 \mathrm{~h}$ at $60^{\circ} \mathrm{C}$ under nitrogen atmosphere, the mixture was natually cooled down to room temperature and filtered. The products obtained were washed with $\mathrm{MeOH} / \mathrm{DDW} / \mathrm{DMF}$ (1:1:1 in volume), and then treated with $6 \mathrm{M} \mathrm{HCl}$ solution for $12 \mathrm{~h}$ to remove $\mathrm{Pb}(\mathrm{II})$ imprinted in IMCNTs. The final products were cleaned with DDW for several times until acid-free, and then dried under vacuum at $70^{\circ} \mathrm{C}$ for $48 \mathrm{~h}$. Non-IMCNTs were prepared similarly in the absence of $\left(\mathrm{CH}_{3} \mathrm{COO}\right)_{2} \mathrm{~Pb} \cdot 3 \mathrm{H}_{2} \mathrm{O}$.

\subsection{Enrichment of $\mathrm{Pb}$ (II)}

\subsubsection{Batch Process}

The $\mathrm{pH}$ values of $\mathrm{Pb}(\mathrm{II})$ standard and sample solution were adjusted to the desired with $0.1 \mathrm{~mol} \cdot \mathrm{L}^{-1} \mathrm{HNO}_{3}$ or $0.1 \mathrm{~mol} \cdot \mathrm{L}^{-1} \mathrm{NH}_{3} \cdot \mathrm{H}_{2} \mathrm{O}$, and the volume was adjusted as desired with DDW. After that, $30 \mathrm{mg}$ of IMCNTs or Non-IMCNTs were added, and the mixed solution was shaken vigorously for 30 mins. Thereafter, the solution was centrifuged, and the concentrations of the metal ions in the filtrate were directly determined by AAS. The adsorbing IMCNTs were eluted with $10 \mathrm{~mL} \mathrm{HCl}(6 \mathrm{M})$ solution, and the concentrations of the metal ions in the eluent were also determined by AAS. Unless otherwise stated, each measured value is mean to three replicates. $\mathrm{Pb}$ (II)-IMCNTs-elute was used to denote these MCNTs eluted.

\subsubsection{Parameters}

The amount of $\mathrm{Pb}(\mathrm{II})$ adsorbed on the MCNTs $(Q)$, the distribution ratio $\left(K_{d}\right)$, the selectivity coefficient $(k)$ and the relative selectivity coefficient $\left(k^{\prime}\right)$ were calculated using the following equations, respectively:

$$
\begin{aligned}
& Q=\frac{\left(C_{0}-C_{t}\right)}{W} V \\
& K_{d}=\frac{\left(C_{0}-C_{t}\right)}{C_{t}} \frac{V}{W} \\
& k=\frac{K_{d-P b}}{K_{d-X}} \\
& k^{\prime}=\frac{k_{I M C N T s}}{k_{N I M C N T s}}
\end{aligned}
$$

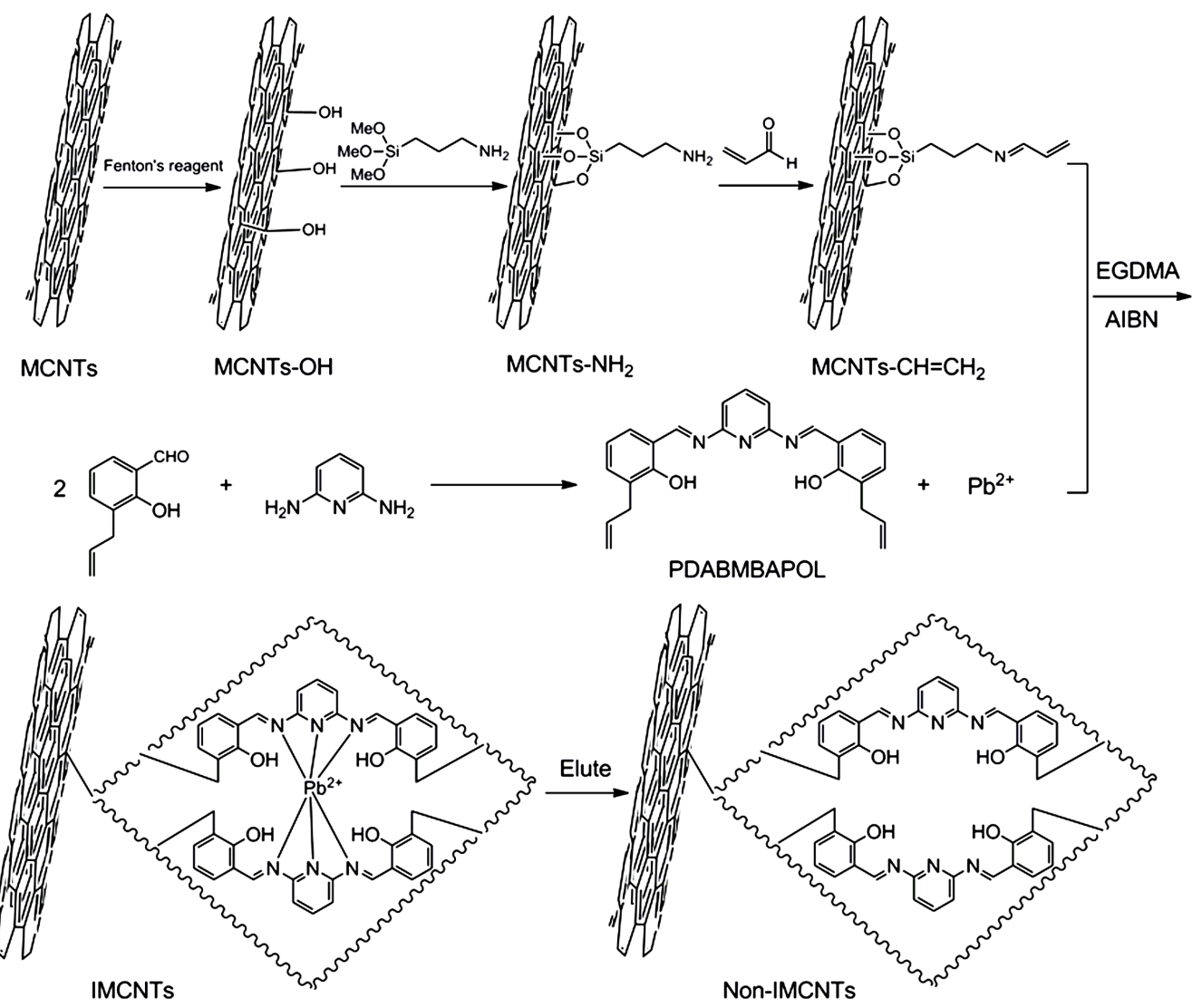

Scheme 1. Preparation of IMCNTS and Non-IMCNTS. 
where $C_{0}$ and $C_{0}$ are the initial and equilibrium concentrations of metal ions $\left(\mathrm{mg} \cdot \mathrm{mL}^{-1}\right)$, respectively. $W$ is the mass of $\mathrm{Pb}$ (II)-ion-imprinted or non-imprinted carbon nanotube $(\mathrm{g})$ and $V$ is the volume of metal ion solution (mL). $X$ is the interfering ion. $K_{d-P b}$ and $K_{d-X}$ represent the distribution ratios of $\mathrm{Pb}(\mathrm{II})$ and $\mathrm{Cd}(\mathrm{II}), \mathrm{Cu}(\mathrm{II})$, $\mathrm{Ni}(\mathrm{II}) . \quad k_{I M C N T S}$ and $k_{\text {NIMCNTS }}$ represent the selectivity factor of imprinted sorbent and non-imprinted sorbent, respectively.

\section{Results and Discussion}

\subsection{Characterization}

FT-IR spectra was used to confirm functional groups on the IMCNTs (Figure 1). Compared with the original MCNTs, the IMCNTs, whether adsorbing $\mathrm{Pb}(\mathrm{II})$ or not, or being eluted, presented $-\mathrm{C}=\mathrm{N}$ - bond locating around $1681.75-1724.29 \mathrm{~cm}^{-1}$, and $-\mathrm{OH}$ bond around $3650 \mathrm{~cm}^{-1}$ $[15,18,23,24]$. These phenomena demonstrated that the functional groups had been grafted onto the surface of IMCNTs. With Non-IMCNTs and Pb(II)-IMCNTs-elute (curve $\mathrm{b}$ and $\mathrm{d}$ ), there were almost no difference between their FT-IR spectra, demonstrating $\mathrm{Pb}$ (II) was removed from the IMCNTs completely. However, for $\mathrm{Pb}(\mathrm{II})$ IMCNTs saturated, it wasn't the case. The characteristic absorption peak of $-\mathrm{C}=\mathrm{N}$ - groups shifted from 1681.75 $\mathrm{cm}^{-1}$ (curve b, d) to $1724.29 \mathrm{~cm}^{-1}$ (curve c), suggesting the $\mathrm{Pb}$ (II) ions had been imprinted on IMCNTs. In curves $\mathrm{b}, \mathrm{c}$ and $\mathrm{d}$, the absorption peak at $3650 \mathrm{~cm}^{-1}$, was attributed to $\gamma \mathrm{O}-\mathrm{H}$. This suggested that $-\mathrm{OH}$ had not been coordinated with $\mathrm{Pb}(\mathrm{II})$.

The surface morphologies of MCNTs and $\mathrm{Pb}$ (II)-imprinted functionalized MCNTs were shown in Figure 2. Apparently, the surface of MCNTs was smooth. On the contrary, the IMCNTs appear porous, rough, irregular and agglomerative.

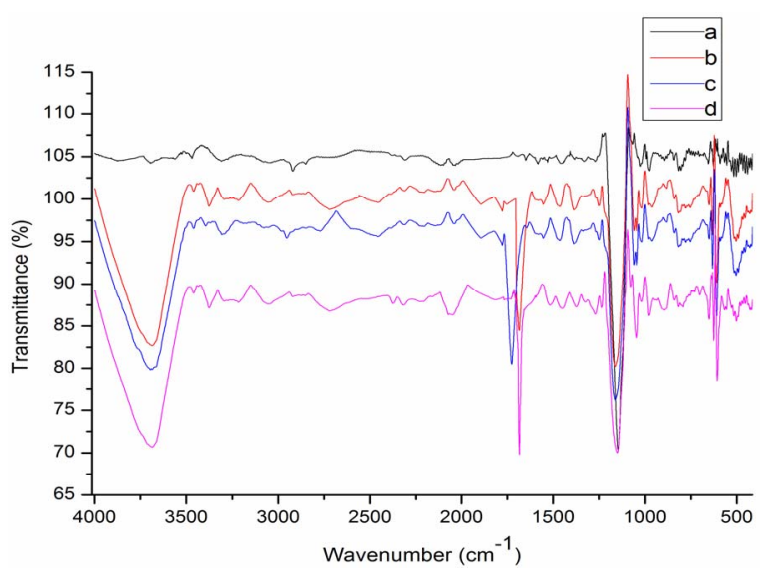

Figure 1. FT-IR spectra of MCNTs (a), Non-IMCNTS (b), IMCNTs saturated with $\mathrm{Pb}(\mathrm{II})$ (c) and $\mathrm{Pb}(\mathrm{II})-\mathrm{IMCNTs-}$ elute (d).

\subsection{Effect of $\mathbf{p H}$}

The effect of $\mathrm{pH}$ on $\mathrm{Pb}$ (II) uptake was investigated using batch process. Because of the hydrolysis of $\mathrm{Pb}$ (II) ion in strong alkali solution, all the experiments were carried out under $\mathrm{pH}$ lower than 7.0. Figure 3 showed that the adsorption of lead was strongly affected by $\mathrm{pH}$ of the solution. The enrichment efficiency of lead was very low at $\mathrm{pH}$ below 2, because the protonation made the bonding capability of adsorbent decrease. From pH 2.0 to 4.0, the adsorption efficiency increased sharply with increasing $\mathrm{pH}$. The recoveries of $\mathrm{Pb}$ (II) were $95.6 \%-97.5 \%$ with in the $\mathrm{pH}$ range of $4.0-6.0$. Here, $\mathrm{pH} 4.0$ was a relatively optimal condition for adsorbing $\mathrm{Pb}(\mathrm{II})$, and subsequent experiments were made at $\mathrm{pH}$ 4.0.

\subsection{Kinetic Experiment}

Uptake kinetics of $\mathrm{Pb}(\mathrm{II})$ on the IMCNTs were investigated using batch process. After adjusted $\mathrm{pH}$ to $4.0, \mathrm{~Pb}$ (II) aqueous solution $\left(25 \mathrm{~mL}, 10 \mu \mathrm{g} \cdot \mathrm{mL}^{-1}\right)$ was mixed with $30 \mathrm{mg}$ IMCNTs. During the process of absorbing, $\mathrm{Pb}(\mathrm{II})$

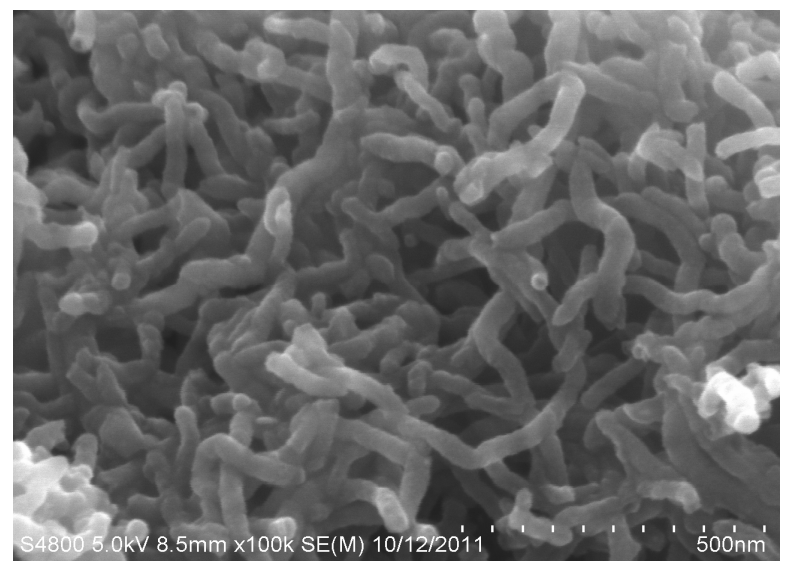

(a)

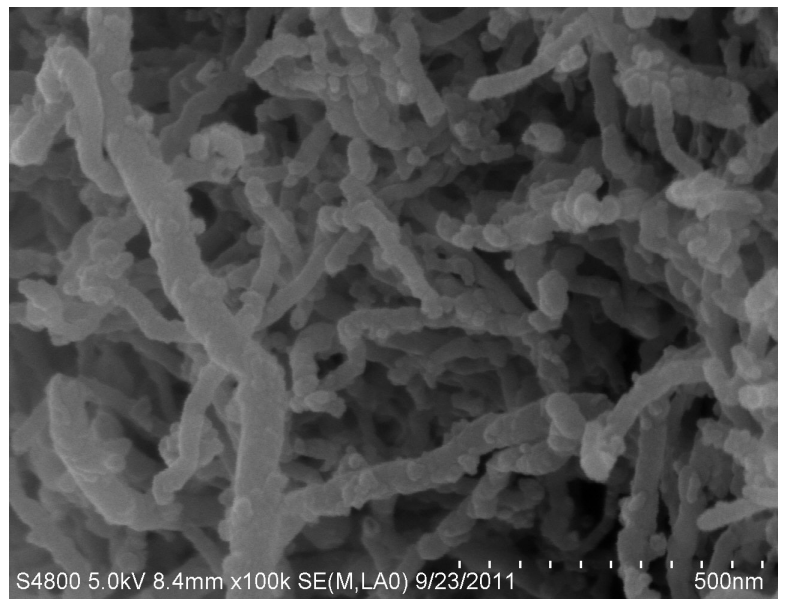

(b)

Figure 2. SEM images of MCNTs (a) and IMCNTS (b). 
concentration in the suspension was determined every 3 min. Figure 4 showed that only 11 mins. was enough for extracting $98.5 \% \mathrm{~Pb}$ (II) of the solution and plateau values were gradually attained within 17 mins, owing to the high complexation rate between $\mathrm{Pb}(\mathrm{II})$ ions and functional ligand of IMCNTs.

\subsection{Static Adsorption Capacity}

Adsorption capacity of the IMCNTs and Non-IMCNTs was investigated using batch experiments. The concentration of $\mathrm{Pb}$ (II) ion in the initial solution ranged from 20 to $180 \mu \mathrm{g} \cdot \mathrm{mL}^{-1}$. Figure 5 showed that the adsorption amount increased with increasing the initial concentration of $\mathrm{Pb}$ (II). When the initial concentration of $\mathrm{Pb}$ (II) was large enough, a plateau began. The maximum $\mathrm{Pb}$ (II) adsorption capacity of the IMCNTs was $115.5 \mathrm{mg} \cdot \mathrm{g}^{-1}$, much higher than that of Non-IMCNTs $\left(84.4 \mathrm{mg} \cdot \mathrm{g}^{-1}\right)$.

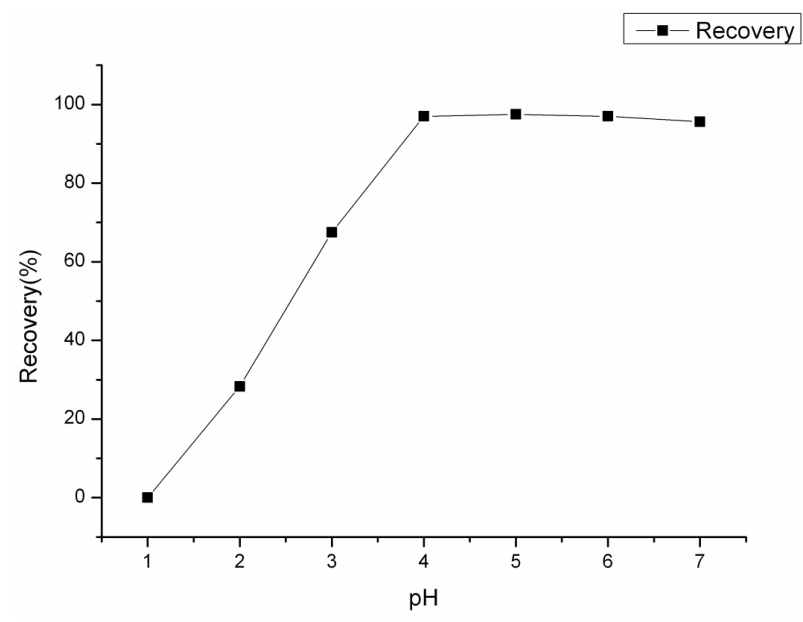

Figure 3. Effect of $\mathrm{pH}$ on sorbent of $\mathrm{Pb}(\mathrm{II})$; other conditions: Sorbent $30 \mathrm{mg}, \mathrm{Pb}(\mathrm{II}) 10 \mu \mathrm{g} \cdot \mathrm{mL}^{-1}$, V $25 \mathrm{~mL}$, T $298 \mathrm{~K}$.

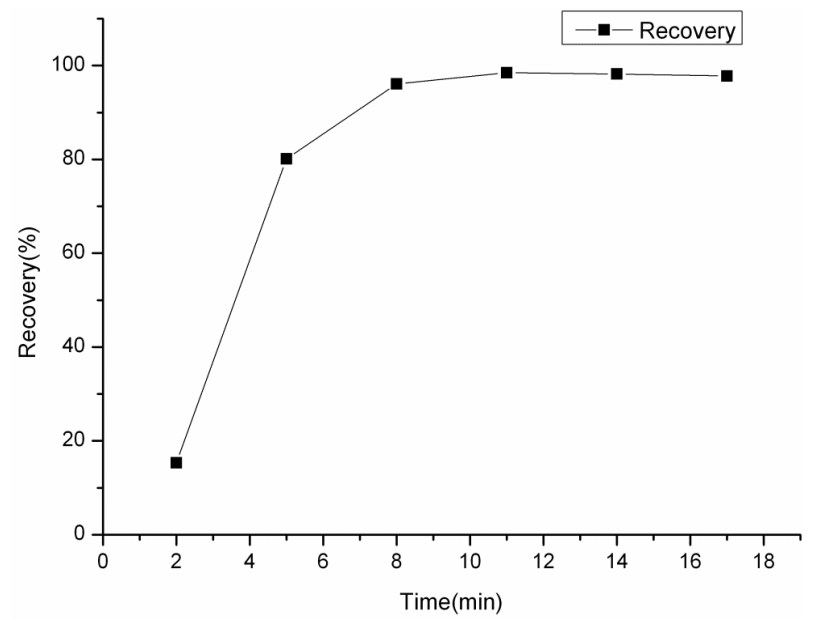

Figure 4. Effect of equilibrium time on sorbent of $\mathrm{Pb}(\mathrm{II}), \mathrm{C}_{0}$ $10 \mu \mathrm{g} \cdot \mathrm{mL}^{-1}$.

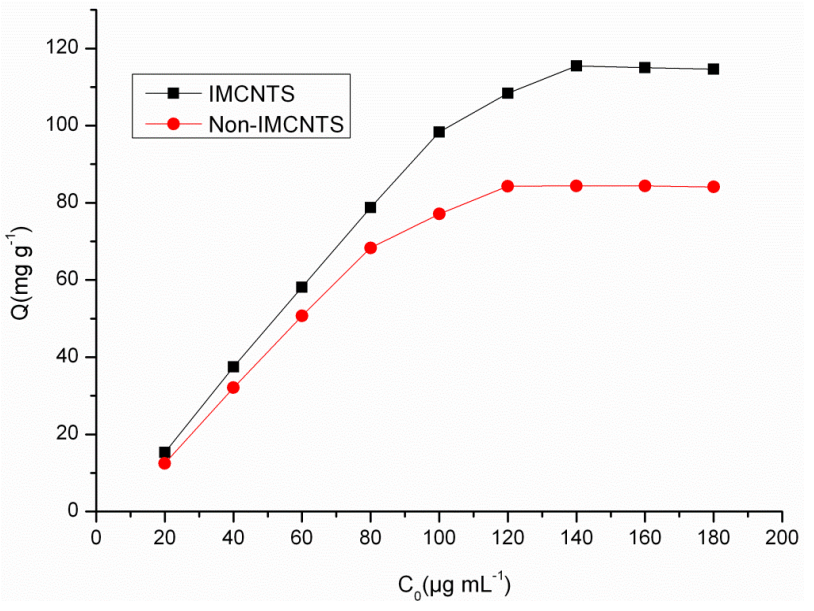

Figure 5. Effect of $\mathrm{Pb}(\mathrm{II})$ initial concentration on the adsorption quantity of IMCNTS and Non-IMCNTS. Other conditions: Sorbent $30 \mathrm{mg}, \mathrm{V} 25 \mathrm{~mL}$, pH 4.0, T 298 K.

\subsection{Thermodynamics of Adsorption}

The effect of temperature on the adsorption equilibrium of $\mathrm{Pb}$ (II) ion was analyzed for IMCNTs in the temperature range from 298.15 to $318.15 \mathrm{~K}$. Thermodynamic parameters such as standard Gibbs free energy change $\left(\Delta G^{\mathrm{o}}, \mathrm{kJ} \cdot \mathrm{mol}^{-1}\right)$, enthalpy change $\left(\Delta H^{\mathrm{o}}, \mathrm{kJ} \cdot \mathrm{mol}^{-1}\right)$, and entropy change $\left(\Delta S^{\circ}, \mathrm{kJ} \cdot(\mathrm{mol} \cdot \mathrm{K})^{-1}\right)$ were calculated using the following equations:

$$
\begin{aligned}
& \Delta G^{\circ}=-R T \ln K \\
& \Delta G^{\circ}=\Delta H^{\circ}-T \Delta S^{\circ} \\
& \ln K=\frac{\Delta S^{\circ}}{R}-\frac{\Delta H^{\circ}}{R T}
\end{aligned}
$$

where $K$ is equilibrium constant $\left(K=C_{a} / C_{s}, C_{a}\right.$ and $C_{s}$ are the equilibrium concentration of $\mathrm{Pb}(\mathrm{II})$ on adsorbent and in the solution, respectively), $T$ is absolute temperature $(K)$, and $R$ is the gas constant $(R=8.314$ $\left.\mathrm{J} \cdot(\mathrm{K} \cdot \mathrm{mol})^{-1}\right)$.

The plot of $\ln K$ against $1 / T$ is shown in Figure 6. According to Equation (7), the slope and intercept of the straight line in Figure 6 corresponds to $-\Delta H^{\circ} / R$ and $\Delta S^{\circ} / R$ respectively. Therefore, $\Delta H^{\circ}$ and $\Delta S^{\circ}$ were calculated to be $70.12 \mathrm{~kJ} \cdot \mathrm{mol}^{-1}$ and $0.27 \mathrm{~kJ} \cdot(\mathrm{mol} \cdot \mathrm{K})^{-1}$, respectively. By Equation (5), $\Delta G^{\mathrm{o}}$ at various temperature was calculated as $-10.37 \mathrm{~kJ} \cdot \mathrm{mol}^{-1}(298.15 \mathrm{~K})$, $-11.72 \mathrm{~kJ} \cdot \mathrm{mol}^{-1}(303.15 \mathrm{~K}),-13.07 \mathrm{~kJ} \cdot \mathrm{mol}^{-1}(308.15 \mathrm{~K})$, $-14.42 \mathrm{~kJ} \cdot \mathrm{mol}^{-1}(313.15 \mathrm{~K})$, and $-15.77 \mathrm{~kJ} \cdot \mathrm{mol}^{-1}$ $(318.15 \mathrm{~K})$. The positive $\Delta H^{\mathrm{o}}$ indicates the endothermic character of the adsorption process, however, the negative $\Delta G^{\circ}$ reveals the adsorption spontaneous nature of $\mathrm{Pb}(\mathrm{II})$. The positive $\Delta \mathrm{S}^{\circ}$ represents a chaos increase in the adsorption process. 


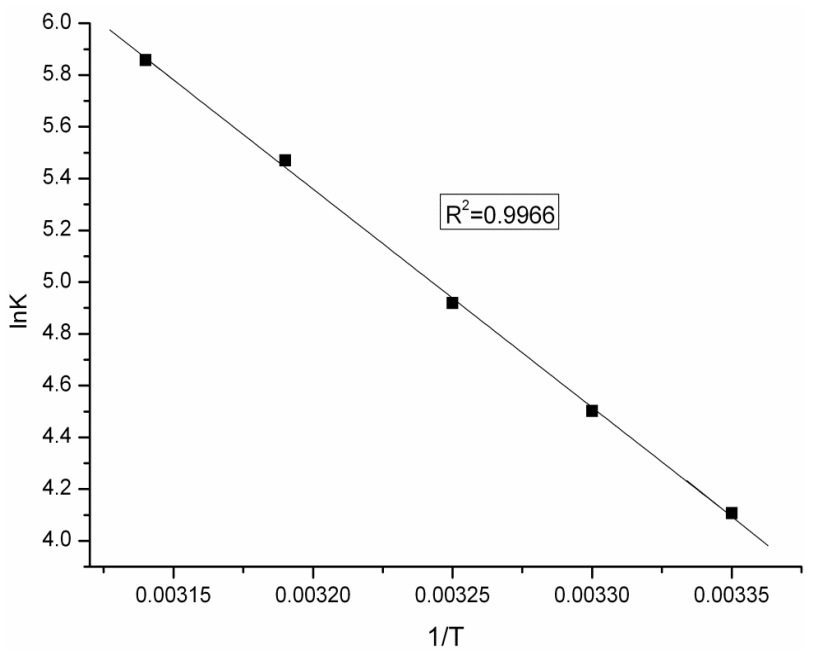

Figure 6. Effect of temperature on sorbent of $\mathrm{Pb}(\mathrm{II})$ on IMCNTS. Pb(II) $10 \mu \mathrm{g} \cdot \mathrm{mL}^{-1}$, V $25 \mathrm{~mL}$, pH 4.0.

\subsection{Cycling and Reproducibility of Pb(II)-IMCNTs}

$\mathrm{Pb}(\mathrm{II})$-IMCNTs, were subjected to adsorption-desorption cycles in a batch process to test their reproducibility and cycling behavior. $6 \mathrm{M} \mathrm{HCl}(10 \mathrm{~mL})$ acted as a desorption agent. The recycled $\mathrm{Pb}(\mathrm{II})-\mathrm{IMCNT}$ presented a recovery not less than $95 \%$ at the 10th cycle, suggesting an adsorption capacity loss only by about $4 \%$. Therefore, it can be concluded that the IMCNTs can be used repeatedly without compromising their adsorption capacities, noticeably.

\subsection{Selectivity of the IMCNTs}

The selectivity of an imprinted material for a given ion plays the key role in its practical use. This paper has estimated the selectivity of the imprinted MCNTs for $\mathrm{Pb}(\mathrm{II})$ relative to $\mathrm{Cd}(\mathrm{II}), \mathrm{Cu}(\mathrm{II})$ and $\mathrm{Ni}(\mathrm{II})$, separately. Each metal ion in its solution had the concentration of 10 $\mu \mathrm{g} \cdot \mathrm{mL}^{-1}$. As shown in Table 1, with IMCNTs, the relative selectivity coefficients $\left(k^{\prime}\right)$ of $\mathrm{Pb}(\mathrm{II}) / \mathrm{Cd}(\mathrm{II}), \mathrm{Pb}(\mathrm{II}) /$ $\mathrm{Cu}$ (II) and $\mathrm{Pb}(\mathrm{II}) / \mathrm{Ni}(\mathrm{II})$, were 21.6, 5.5 and 22, respectively, greater than one, indicating IMCNTs displayed higher selectivity for $\mathrm{Pb}$ (II) relative to $\mathrm{Cd}(\mathrm{II}), \mathrm{Cu}$ (II) and Ni(II). Therefore, the above IMCNTs could be applied to selectively separating $\mathrm{Pb}$ (II) from the solution containing $\mathrm{Cd}(\mathrm{II}), \mathrm{Cu}(\mathrm{II})$ and $\mathrm{Ni}(\mathrm{II})$. Two possible factors contributed to the higher selectivity for $\mathrm{Pb}$ (II) in the presence of the above competitive ions. One was the holes size selectivity. The size of $\mathrm{Pb}$ (II) ion cut out for the cavity of the IMCNTs. The other was the coordination geometry selectivity. IMCNTs could provide ligand groups with preferred selectivity for $\mathrm{Pb}(\mathrm{II})$ ions.

\subsection{Accuracy and Precision of the Analytical Method}

The accuracy and precision of the analytical method were evaluated by repeating the experiment for eight times under the optimal experimental conditions. The results indicated that the precision of the method, evaluated as the relative standard deviation ( $\mathrm{RSD}, \mathrm{n}=8$ ), was $1.16 \%$. The limit of detection (LOD), calculated based on the three times of the blank standard deviation of eight runs the blank solution, was $0.47 \mu \mathrm{g} \cdot \mathrm{L}^{-1}$. This indicated that the method had good precision for the analysis of trace $\mathrm{Pb}(\mathrm{II})$.

\subsection{Application of the Proposed Method}

The accuracy of the method was evaluated by determining the amount of $\mathrm{Pb}^{2+}$ ions in the certified reference material and three environmental water samples (River water, Tap water, Waste water). For water samples, the standard addition method was adopted. From Table 2, it could be seen that the estimated values agreed well with the certified values. The recoveries of $\mathrm{Pb}(\mathrm{II})$ ions were in

Table 1. Competitive sorption of $\mathrm{Pb}$ (II) and metal ions on IMCNTs and NIMCNTs at pH 4.0.

\begin{tabular}{cccccc}
\hline $\begin{array}{c}\text { Mixture of ions } \\
\left(10 \mu \mathrm{g} \cdot \mathrm{mL}^{-1}, 250 \mathrm{~mL}\right)\end{array}$ & $\begin{array}{c}K_{d-I M C N T S} \\
\left(\mathrm{~mL} \cdot \mathrm{g}^{-1}\right)\end{array}$ & $\begin{array}{c}K_{d-N I M C N T S} \\
\left(\mathrm{~mL} \cdot \mathrm{g}^{-1}\right)\end{array}$ & $k_{I M C N T S}$ & $k_{\text {NIMCNTS }}$ & $k^{\prime}$ \\
\hline $\mathrm{Pb}(\mathrm{II}) / \mathrm{Cd}(\mathrm{II})$ & $1658.3 / 64$ & $21.7 / 18.1$ & 25.9 & 1.2 & 21.6 \\
$\mathrm{~Pb}(\mathrm{II}) / \mathrm{Cu}(\mathrm{II})$ & $1646 / 71$ & $33 / 7.9$ & 23.2 & 4.2 & 5.5 \\
$\mathrm{~Pb}(\mathrm{II}) / \mathrm{Ni}(\mathrm{II})$ & $1613 / 67$ & $20.1 / 18.7$ & 24.1 & 1.1 & 22 \\
\hline
\end{tabular}

Table 2. Determination of $\mathrm{Pb}(\mathrm{II})$ in environmental water samples.

\begin{tabular}{cclc}
\hline Sample & $\begin{array}{c}\mathrm{Pb}(\mathrm{II}) \text { added } \\
\left(\mu \mathrm{g} \cdot \mathrm{L}^{-1}\right)\end{array}$ & $\begin{array}{c}\mathrm{Pb}(\mathrm{II}) \text { founded } \\
\left(\mu \mathrm{g} \cdot \mathrm{L}^{-1}\right)\end{array}$ & $\begin{array}{c}\text { Recovery } \\
(\%)\end{array}$ \\
\hline \multirow{3}{*}{ GBW08619 } & 0 & $\mathrm{BQL}^{\mathrm{b}}$ & \\
& $5.0^{\mathrm{a}}$ & $4.85 \pm 0.02$ & 97.0 \\
River water & $10.0^{\mathrm{a}}$ & $9.75 \pm 0.03$ & 97.5 \\
& 0 & $0.59 \pm 0.01$ & - \\
& 5.0 & $5.76 \pm 0.06$ & 103.0 \\
Tap water & 10.0 & $10.57 \pm 0.12$ & 99.8 \\
& 0 & $\mathrm{BQL}$ & - \\
& 5.0 & $4.98 \pm 0.07$ & 99.6 \\
Waste water & 10.0 & $10.01 \pm 0.11$ & 100.1 \\
& 0 & $1.17 \pm 0.02$ & - \\
& 5.0 & $6.24 \pm 0.08$ & 101.1 \\
\hline
\end{tabular}

${ }^{a}$ Reference value. The certified sample solution was accurately diluted to 5 and $10 \mu \mathrm{g} \cdot \mathrm{L}^{-1}$, respectively; ${ }^{\mathrm{b}}$ Below the quantification limit. 
Table 3. Comparisons of maximum adsorption capacity, analytical precision and accuracy of different SPE materials for pre-concentration of $\mathrm{Pb}(\mathrm{II})$.

\begin{tabular}{lcccc}
\hline $\begin{array}{c}\text { SPE material coupled with } \\
\text { analytical technique }\end{array}$ & $\begin{array}{c}\text { The maximum adsorption } \\
\text { capacity }\left(\mathrm{mg} \cdot \mathrm{g}^{-1}\right)\end{array}$ & $\begin{array}{c}\text { LOD } \\
\left(\mathrm{ng} \cdot \mathrm{mL}^{-1}\right)\end{array}$ & $\begin{array}{c}\text { R.S.D } \\
(\%)\end{array}$ & Ref. \\
\hline P2AT modified MWCNTs/AAS & 186.4 & 1 & 3.2 & {$[25]$} \\
PANI modified MWCNTs/UV & 22.2 & $\mathrm{ND}$ & $\mathrm{ND}$ & {$[26]$} \\
Column SPE on MWCNTs/AAS & $\mathrm{ND}^{*}$ & 8.0 & $<2.5$ & {$[27]$} \\
IDA modified MWCNTs/ICP-MS & 8.98 & 0.00070 & 1.0 & {$[28]$} \\
IMCNTs/AAS & 115.5 & 0.47 & 1.16 & Present work \\
\hline
\end{tabular}

*ND: not detected.

the range of $97.0 \%-103.0 \%$. The comparisons of maximum adsorption capacity, analytical precision and accuracy of different $\mathrm{SPE}$ materials for $\mathrm{Pb}$ (II) was given in Tables 3. As could be seen, the present analytical method was comparable with that obtained by other reported different SPE materials in recent years. These results clearly demonstrated that the IMCNTs prepared were highly efficient, suitable and satisfactory for extracting and determining $\mathrm{Pb}(\mathrm{II})$ ions.

\section{Conclusion}

The newly IMCNTs was synthesized using a complex of PDABMBAPOL with $\mathrm{Pb}(\mathrm{II})$ as functional monomer and template ion. The IMCNTs exhibited high affinity, selectivity and fast kinetics for $\mathrm{Pb}(\mathrm{II})$ ions. Under optimal conditions, the maximum adsorption quantity of IMCNTs was $115.5 \mathrm{mg} \cdot \mathrm{g}^{-1}$ much higher than that of NonIMCNTs $\left(84.4 \mathrm{mg} \cdot \mathrm{g}^{-1}\right)$. The presence of other metal ions such as $\mathrm{Cd}(\mathrm{II}), \mathrm{Cu}(\mathrm{II})$, or Ni(II) did not affect IMCNTs selectivity for $\mathrm{Pb}$ (II). Separation and pre-concentration by solidphase extraction with IMCNTs particles results in a limit of detection of $0.47 \mu \mathrm{g} \cdot \mathrm{L}^{-1}(3 \sigma)$ and $\mathrm{RSD}(\mathrm{n}=$ 8 ) of $1.16 \%$ by using AAS. In addition, the IMCNTs prepared had high reproducibility and were efficient, sensitive and reliable for the enrichment and determination of trace lead.

\section{Acknowledgements}

This research was supported by the National Natural Science Foundation of China (No. 11175080) and by the Nature Science Fund of the Hunan Province (No. 10JJ6025).

\section{REFERENCES}

[1] C. Esen, M. Andac, N. Bereli, R. Say, E. Henden and A. Denizli, "Highly Selective Ion-Imprinted Particles for Solid-Phase Extraction of $\mathrm{Pb}^{2+}$ Ions," Materials Science and Engineering C, Vol. 29, No. 8, 2009, pp. 2464-2470. doi:10.1016/j.msec.2009.07.012

[2] L. M. Wang, M. H. Zhou, Z. J. Jing and A. F. Zhong,
"Selective Separation of Lead from Aqueous Solution with a Novel $\mathrm{Pb}$ (II) Surface Ion-Imprinted Sol-Gel Sorbent," Microchimica Acta, Vol. 165, No. 3-4, 2009, pp. 367-372. doi:10.1007/s00604-009-0146-2

[3] F. Q. An, B. J. Gao and X. Q. Feng, "Adsorption and Recognition Properties of Ionic Imprinted Polyamine IIP-PEI/SiO $\mathrm{S}_{2}$ towards $\mathrm{Pb}^{2+}$ Ion," Journal of Applied Polymer Science, Vol. 112, No. 4, 2009, pp. 2241-2246. doi:10.1002/app.29751

[4] H. X. Shan, Z. J. Li and M. Li, "Ionic Liquid 1-Octyl3-methylimidazolium Hexafluorophosphate as a Solvent for Extraction of Lead in Environmental Water Samples with Detection by Graphite Furnace Atomic Absorption Spectrometry," Microchimica Acta, Vol. 159, No. 1-2, 2007, pp. 95-100. doi:10.1007/s00604-006-0720-9

[5] J. Otero-Romaní, A. Moreda-Pineiro, P. Bermejo-Barrera and A. Martin-Esteban, "Inductively Coupled PlasmaOptical Emission Spectrometry/Mass Spectrometry for the Determination of $\mathrm{Cu}, \mathrm{Ni}, \mathrm{Pb}$ and $\mathrm{Zn}$ in Seawater after Ionic Imprinted Polymer Based Solid Phase Extraction," Talanta, Vol. 79, No. 3, 2009, pp. 723-729. doi:10.1016/j.talanta.2009.04.066

[6] X. B. Zhu, Y. M. Cui, X. J. Chang, X. J. Zou and Z. H. Li, "Selective Solid-Phase Extraction of lead(II) from Biological and Natural Water Samples Using SurfaceGrafted Lead(II)-Imprinted Polymers," Microchimica Acta, Vol. 164, No. 1-2, 2009, pp. 125-132. doi:10.1007/s00604-008-0045-y

[7] S. Daniel, P. P. Rao and T. P. Rao, "Investigation of Different Polymerization Methods on the Analytical Performance of Palladium(II) Ion Imprinted Polymer Materials" Analytica Chimica Acta, Vol. 536, No. 1-2, 2005, pp. 197-206. doi:10.1016/i.aca.2004.12.052

[8] M. Shamsipur, J. Fasihi and K. Ashtari, "Grafting of Ion-Imprinted Polymers on the Surface of Silica Gel Particles through Covalently Surface-Bound Initiators: A Selective Sorbent for Uranyl Ion," Analytical Chemistry, Vol. 79, No. 18, 2007, pp. 7116-7123. doi:10.1021/ac070968e

[9] N. Jiang, X. J. Chang, H. Zheng, Q. He and Z. Hu, "Selective Solid-Phase Extraction of Nickel(II) Using a Surface-Imprinted Silica Gel Sorbent," Analytica Chimica Acta, Vol. 577, No. 2, 2006, pp. 225-231. doi:10.1016/j.aca.2006.06.049

[10] Z. Q. Cheng, H. Q. Wang, Y. Y. Wang, F. F. He, H. S. 
Zhang and S. Q. Yang, "Synthesis and Characterization of an Ion-Imprinted Polymer for Selective Solid Phase Extraction of Thorium(IV)," Microchimica Acta, Vol. 173, No. 3-4, 2011, pp. 423-431. doi:10.1007/s00604-011-0576-5

[11] N. García-Otero, C. Teijeiro-Valiño, J. Otero-Romaní, E. Peña-Vázquez, A. Moreda-Piñeiro and P. BermejoBarrera, "On-Line Ionic Imprinted Polymer Selective Solid-Phase Extraction of Nickel and Lead from Seawater and Their Determination by Inductively Coupled PlasmaOptical Emission Spectrometry," Analytical and Bioanalytical Chemistry, Vol. 395, No. 4, 2009, pp. 1107-1115. doi:10.1007/s00216-009-3044-X

[12] H. Zheng, D. Zhang, W. Y. Wang, Y. Q. Fan, J. Li and H. P. Han, "Highly Selective Determination of Palladium(II) after Preconcentration Using Pd(II)-Imprinted Functionalized Silica Gel Sorbent Prepared by a Surface Imprinting Technique," Microchimica Acta, Vol. 157, No.1-2, 2007, pp. 7-11. doi:10.1007/s00604-006-0649-Z

[13] Y. Li, X. Li, J. Chu, C. Dong, J. Qi and Y. Yuan, "Synthesis of Core-Shell Magnetic Molecular Imprinted Polymer by the Surface RAFT Polymerization for the Fast and Selective Removal of Endocrine Disrupting Chemicals from Aqueous Solutions," Environmental Pollution, Vol. 158, No. 6, 2010, pp. 2317-2323. doi:10.1016/i.envpol.2010.02.007

[14] C. R. T. Tarley, F. N. Andrade, F. M. de Oliveira, M. Z. Corazza, L. F. M. de Azevedo and M. G. Segatelli, "Synthesis and Application of Imprinted Polyvinylimidazole-Silica Hybrid Copolymer for $\mathrm{Pb}^{2+}$ Determination by Flow-Injection Thermospray Flame Furnace Atomic Absorption Spectrometry," Analytica Chimica Acta, Vol. 703, No. 2, 2011, pp. 145-151. doi:10.1016/i.aca.2011.07.029

[15] G. Z. Fang, J. Tan and X. P. Yan, "An Ion-Imprinted Functionalized Silica Gel Sorbent Prepared by a Surface Imprinting Technique Combined with a Sol-Gel Process for Selective Solid-Phase Extraction of Cadmium(II)," Analytical Chemistry, Vol. 77, No. 6, 2005, pp. 17341739. doi:10.1021/ac048570v

[16] X. J. Wang, Z. L. Xu, N. C. Bing and Z. G. Yang, "Preparation and Aqueous Recognition of Metal Complex Imprinted Polymer Using N-vinyl-2-pyrrolidone as Functional Monomer," Chinese Journal of Chemical Engineering, Vol. 15, No. 4, 2007, pp. 595-599. doi:10.1016/S1004-9541(07)60130-X

[17] S. Hazra, S. Majumder, M. Fleck, R. Koner and S. Mohanta, "Syntheses, Structures, Absorption and Emission Properties of a Tetraiminodiphenol Macrocyclic Ligand and Its Dinuclear $\mathrm{Zn}(\mathrm{II})$ and $\mathrm{Pb}(\mathrm{II})$ Complexes," Polyhedron, Vol. 28, No. 14, 2009, pp. 2871-2878. doi:10.1016/j.poly.2009.06.039

[18] S. Iihan, "Synthesis and Spectral Studies of New Macrocyclic Schiff Base Cu(II), Ni(II), Cd(II), Zn(II), Pb(II), and La(III) Complexes Containing Pyridine Head Unit," Russian Journal of Coordination Chemistry, Vol. 35, No. 5, 2009, pp. 347-351. doi:10.1134/S1070328409050066

[19] S. Ilhan and H. Temel, "Synthesis and Characterization of a New Macrocyclic Schiff Base Derived from 2,6-Diaminopyridine and 1,10-Bis(2-formylphenyl)-1,4,7,10tetraoxadecane and Its $\mathrm{Cu}(\mathrm{II}), \mathrm{Ni}(\mathrm{II}), \mathrm{Pb}(\mathrm{II}), \mathrm{Co}(\mathrm{III})$ and La(III) Complexes," Transition Metal Chemistry, Vol. 32, No. 8, 2007, pp. 1039-1046. doi:10.1007/s11243-007-0276-5

[20] Y. Ying, R. K. Saini, F. Liang, A. K. Sadana and W. E. Billups, "Functionalization of Carbon Nanotubes by Free Radicals," Organic Letters, Vol. 5, No. 9, 2003, pp. 1471-1473. doi:10.1021/o10342453

[21] U. Dettlaff-Weglikowska, J. M. Benoit, P. W. Chiu, R. Graupner, S. Lebedkin and S. Roth, "Chemical Functionalization of Single Walled Carbon Nanotubes," Current Applied Physics, Vol. 2, No. 6, 2002, pp. 497-501. doi:10.1016/S1567-1739(02)00164-5

[22] C. R. Lin, H. Q. Wang, Y. Y. Wang and Z. Q. Cheng, "Selective Solid-Phase Extraction of Trace Thorium(IV) Using Surface-Grafted Th(IV)-Imprinted Polymers with Pyrazole Derivative," Talanta, Vol. 81, 2010, pp. 30-36. doi:10.1016/j.talanta.2009.11.032

[23] J. Pan, S. Wang and R. Zhang, "A Novel Pb(II)-Imprinted IPN for Selective Preconcentration of Lead from Water and Sediments," Analytical Chemistry, Vol. 86, No. 11, 2006, pp. 855-865.

[24] H. Keypour, M. Rezaeivala, L. Valencia and P. PérezLourido, "Synthesis and Characterization of Two Zinc(II) Macrocyclic Schiff-Base Complexes Containing Piperazine Moiety, Crystal Structure of One Complex," Polyhedron, Vol. 28, No. 16, 2009, pp. 3415-3418. doi:10.1016/j.poly.2009.07.012

[25] M. R. Nabida, R. Sedghia, A. Bagheria, M. Behbahania, M. Taghizadeha, H. A. Oskooieb and M. M. Heravib, "Preparation and Application of Poly(2-amino thiophenol)/MWCNTs Nanocomposite for Adsorption and Separation of Cadmium and Lead Ions via Solid Phase Extraction," Journal of Hazardous Materials, Vol. 203204, 2012, pp. 93-100. doi:10.1016/j.jhazmat.2011.11.096

[26] D. D. Shao, C. L. Chen and X. K. Wang, "Application of Polyaniline and Multiwalled Carbon Nanotube Magnetic Composites for Removal of $\mathrm{Pb}(\mathrm{II})$," Chemical Engineering Journal, Vol. 185-186, 2012, pp. 144-150. doi:10.1016/j.cej.2012.01.063

[27] S. G. Ozcan, N. Satiroglu and M. Soylak, "Column Solid Phase Extraction of Iron(III), Copper(II), Manganese(II) and Lead(II) Ions Food and Water Samples on MultiWalled Carbon Nanotubes," Food and Chemical Toxicology, Vol. 48, 2010, pp. 2401-2406. doi:10.1016/j.fct.2010.05.078

[28] J. P. Wang, X. X. Ma, G. Z. Fang, M. F. Pan, X. K. Ye and S. Wang, "Preparation of Iminodiacetic Acid Functionalized Multi-Walled Carbon Nanotubes and Its Application as Sorbent for Separation and Preconcentration of Heavy Metal Ions," Journal of Hazardous Materials, Vol. 186, 2011, pp. 1985-1992. doi:10.1016/i.jhazmat.2010.12.087 